Service social

\title{
Les nouveaux visages de la pauvreté, par Madeleine Gauthier, (dir.), Québec, Institut québécois de recherche sur la culture, 1987, 258 pages.
}

\section{Lise Poulin Simon}

Volume 37, numéro 1-2, 1988

Par-delà les barrières des sexes

URI : https://id.erudit.org/iderudit/706408ar

DOI : https://doi.org/10.7202/706408ar

Aller au sommaire du numéro

Éditeur(s)

École de service social de l'Université Laval

ISSN

1708-1734 (numérique)

Découvrir la revue

Citer ce compte rendu

Simon, L. P. (1988). Compte rendu de [Les nouveaux visages de la pauvreté, par Madeleine Gauthier, (dir.), Québec, Institut québécois de recherche sur la culture, 1987, 258 pages.] Service social, 37(1-2), 290-291.

https://doi.org/10.7202/706408ar d'utilisation que vous pouvez consulter en ligne.

https://apropos.erudit.org/fr/usagers/politique-dutilisation/ 
Il faut remercier ce Collectif d'avoir réuni autant de matériaux disparates et de les avoir organisés d'une façon utile à la personne en quête d'informations sur la condition masculine.

Compte tenu de la nature des informations, aurait-il été mieux de présenter cet ouvrage dans un cahier à anneaux, qui permet les additions fréquentes, plutôt que dans un volume de type habituel? Qu'à cela ne tienne, les auteurs évoquent, à la page 112, la... prochaine édition du répertoire.

Jocelyn LINDSAY

École de service social,

Université Laval.

Les nouveaux visages de la pauvreté, par Madeleine GAUTHIER, (dir.), Québec, Institut québécois de recherche sur la culture, 1987, 258 pages.

Les nouveaux visages de la pauvreté, que vient de publier l'Institut québécois de recherche sur la culture, nous offre un recueil de textes présentant certaines facettes de la pauvreté au Québec. Treize collaborateurs ont participé à cette étude ; quelques-uns rattachés à l'Institut, mais la plupart venus de l'extérieur, dont plusieurs de l'Université Laval.

Le regroupement des textes sous quatre thématiques assure une certaine cohérence à l'étude. La première thématique, " Des situations ", traite du phénomène de la pauvreté à travers l'analyse de son incidence par rapport aux quatre catégories sociales vulnérables : les jeunes, les femmes, les personnes handicapées, les Indiens. La division suivante, "Des témoignages", regroupe quatre textes qui nous amènent à appréhender la pauvreté à travers des témoignages de jeunes, de réfugiés, de chambreurs et par le biais de certains récits québécois. La section "Des stratégies", nous éclaire sur des stratégies sociales de dépannage expérimentées au Québec, d'abord en milieu urbain, grâce à des associations volontaires d'assistance, et ensuite en milieu rural, grâce aux échanges informels qui se tissent pour faire face à la pauvreté. Les trois derniers textes sont à caractère plus théorique : un premier analyse les différentes approches de la mesure quantitative de la pauvreté ; les deux autres questionnent sa dynamique de développement.

Dans le contexte actuel d'une remise en cause de certains aspects de nos programmes de transfert, tels l'aide sociale et l'assurance-chômage, cette étude nous fournit matière à réflexion sur un certain nombre de carences de nos politiques sociales et économiques.

En particulier, l'article sur la pauvreté des femmes nous indique une croissance du phénomène depuis le début des années 1980, due en particulier à des problèmes et à des changements sociaux n'ayant pas été accompagnés des transformations institutionnelles conséquentes et qui nous auraient évité ce pas en arrière dans la lutte à la pauvreté. Il montre par exemple que le risque de la pauvreté est toujours plus élevé pour les femmes et cela, malgré la progression spectaculaire de leur participation au marché du travail. Ceci met en lumière le 
difficile problème des disparités dans les conditions de travail des hommes et des femmes et l'importance de politiques efficaces d'égalité salariale.

L'étude sur les femmes constate également qu'il y a baisse de la pauvreté pour certaines d'entre elles, mais hausse constante chez les familles monoparentales, nouveau phénomène social qui remet en cause un grand nombre de nos politiques et de nos institutions publiques généralement fondées sur le principe d'une famille à deux adultes. Cette nouvelle réalité questionne autre autres nos politiques d'insertion au marché du travail, de transferts des revenus et de support social et économique aux familles. La même étude nous indique également qu'il y a rétrécissement des écarts entre les taux de pauvreté des hommes et des femmes, non pas en raison de la baisse du taux de paurreté des femmes mais tout simplement parce que, depuis le début des années 1980, l'appauvrissement des hommes est plus élevé. La très forte incidence, depuis plus d'une décennie, du chômage prolongé, chez certains jeunes et chez des travailleurs âgés, devait tôt ou tard se refléter sur le taux de pauvreté des hommes. Cette dégradation de leur situation économique met en lumière les carences de nos politiques de l'emploi.

Ce volume devrait être lu par tous ceux qui sont préoccupés par le problème de la pauvreté, mais surtout par ceux qui y sont peut-être moins sensibles et qui sont pourtant responsables de la mise en ceuvre de politiques sociales et économiques adaptées au nouveau visage social du Québec.

Lise PouLIN SIMON

Département des relations industrielles, Université Laval.

Riches contre pauvres - Deux poids, deux mesures, par Denis ForTin, Québec, Les Éditions autogestionnaires, 1988, 235 pages.

Au moment même où les accusations les plus lourdes pèsent contre les 650000 personnes assistées sociales du Québec, au cœur du débat sur la réforme en profondeur du système d'aide sociale prônée par le gouvernement Bourassa, Denis Fortin lève le voile sur un autre système d'aide sociale prévalant au Québec et au Canada et réservé aux mieux nantis d'entre nous.

Cet ouvrage se divise en deux parties. La première traite essentiellement du régime public d'assistance sociale destiné aux plus démunis de notre société. L'auteur a choisi de nous présenter ce thème en faisant une remontée historique de la conjoncture économique et sociale à travers laquelle s'est inscrite la loi de l'aide sociale. Il passe par les principaux événements qui l'ont modelée depuis vingt ans, jusqu'à l'avènement du Livre blanc sur la fiscalité des particuliers qui dessina les grandes lignes du projet de refonte de l'aide sociale tel qu'on la connaît aujourd'hui. Cette remontée historique nous permet de constater en quoi le "passage d'un État providence à un État provigo"vient menacer nos politiques sociales et, par surcroît, la loi de l'aide sociale. 